\title{
High-Resolution Aeromagnetic Survey to Image Shallow Faults, Dixie Valley Geothermal Field, Nevada
}

\author{
By V. J. S. Grauch
}

U.S. Geological Survey, MS 964, Federal Center, Denver CO 80225

\section{Open-File Report 02-384}

\section{2}

Prepared for the U.S. Department of Energy (DOE)

Under Interagency Agreement DE-AI07-92ID13207, Modifications A014 \& A016

This report is prelininary and has not been reviewed for conformity with U.S. Geological Survey editorial standards or with the North American Stratigraphic Code. Any use of trade, firm, or product names is for descriptive purposes only and does not imply endorsement by the U.S. Government.

U.S. Department of the Interior

U.S. Geological Survey 


\section{TABLE OF CONTENTS}

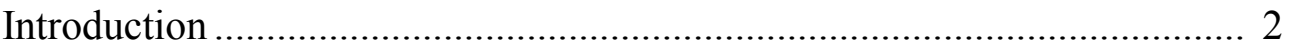

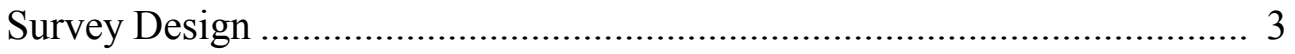

Data Acquisition and Processing.................................................................... 4

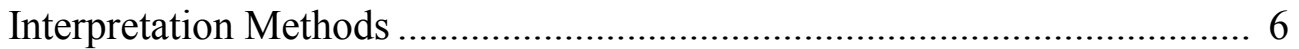

Reduction-to-pole..................................................................... 6

Gradient Window Method................................................................ 7

Anomaly Separation …………………………………………...... 8

Depth Estimation......................................................................... 9

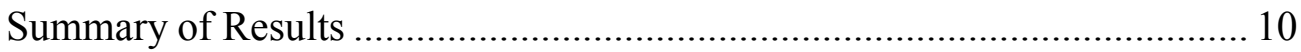

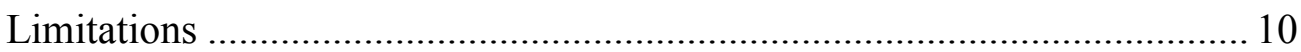

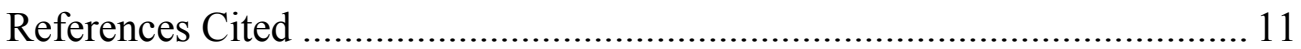

\section{LIST OF FIGURES}

Figure 1. Location of Dixie Valley aeromagnetic survey............................. 2

Figure 2. Total-field magnetic data ……………………………………... 5

Figure 3. Reduced-to-pole (RTP) aeromagnetic data................................... 6

Figure 4. Shaded-relief image of the HGM................................................... 7

Figure 5. Separation of the RTP aeromagnetic data.................................... 8

Figure 6. Interpreted faults, color-coded according to estimated depth ....... 9

\section{LIST OF TABLES}

Table 1. Specifications of the Dixie Valley survey ...................................... 4 


\section{INTRODUCTION}

Understanding the relations between faults and the flow of thermal fluids is key to successful exploration for new geothermal resources in Dixie Valley and other Basin and Range geothermal systems. Mapping fault patterns within these basins and recognizing their connections at depth are key to improving this understanding. However, most of the faults are shallowly buried, making them difficult to locate and map. Moreover, drill holes and seismic profiles cannot give a comprehensive view of fault attitudes and patterns because the information they provide is only for limited areas.

High-resolution aeromagnetic surveys flown over the Albuquerque basin of the Rio Grande rift, New Mexico, have recently demonstrated that aeromagnetic methods can successfully map concealed and poorly exposed faults in a basin environment (Grauch, 2001). The surveys provided a new view of the overall pattern of faulting and allowed general estimates of the attitudes, depths, and geometries of many of the faults (Grauch et al., 2001).

Dixie Valley is situated in an analogous geologic environment to Albuquerque basin and is an excellent case study for a Basin and Range geothermal resource area. To better understand the fault pattern near the geothermal resource area, the Department of Energy contracted the U.S. Geological Survey (USGS) to acquire and process a high-resolution, helicopter-borne magnetic survey (fig. 1). This report briefly describes the acquisition and processing procedures for these data, the interpretation techniques used to image shallow faults, and limitations of these results.

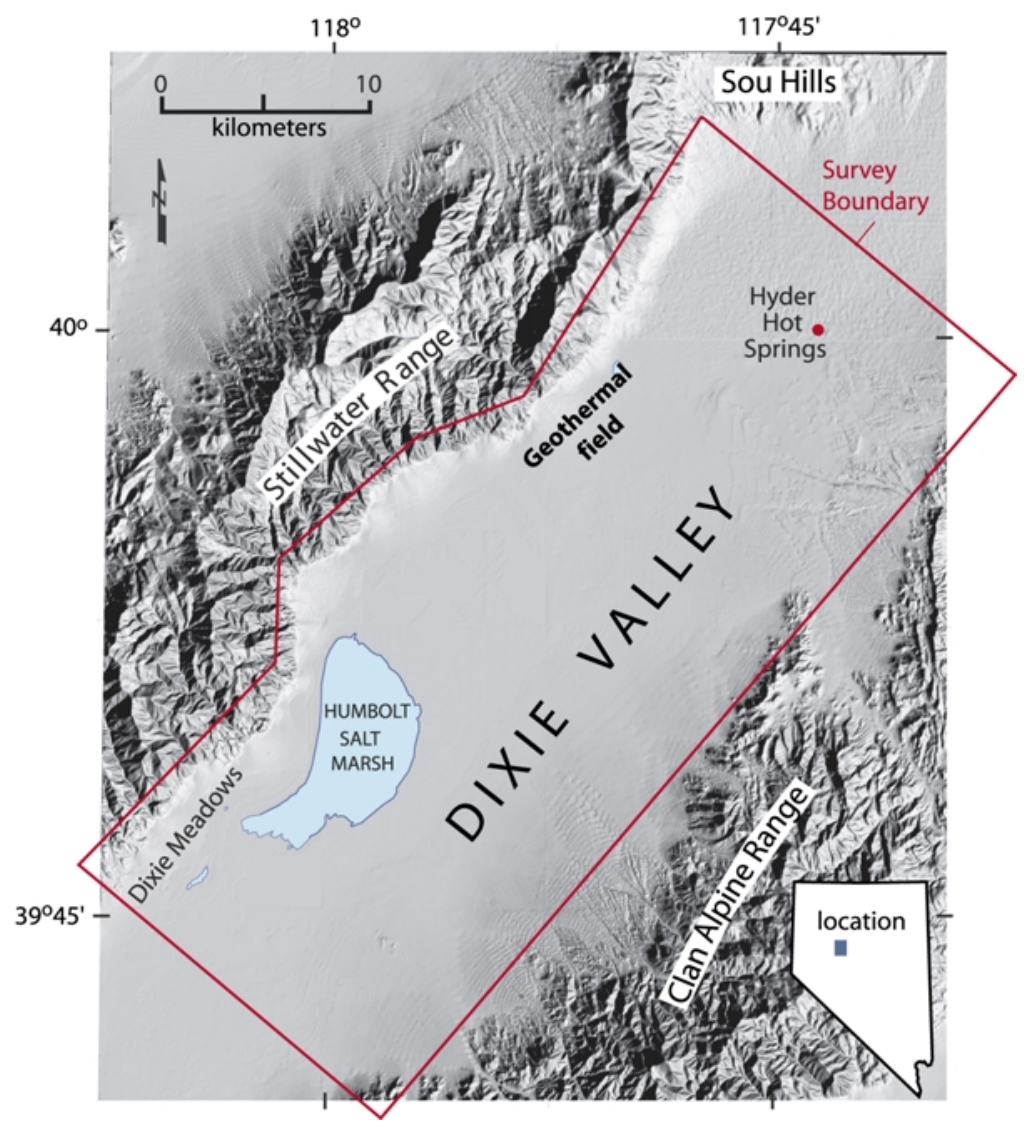

Figure 1. Location of Dixie Valley aeromagnetic survey in relation to topographic features. 


\section{SURVEY DESIGN}

Conventional aeromagnetic surveys are designed to focus on mapping magnetic rocks, such as igneous and metamorphic basement rocks. High-resolution surveys are flown closer to the ground and with narrower line spacing. The difference in survey design allows better detection of subtle magnetic contrasts, such as those arising from the juxtaposition of basin-fill sediments having different lithologies. It also allows for better definition of sources with limited lateral extent, and overall better resolution of details in map view.

Design of the Dixie Valley survey was initially guided by the high-resolution surveys that were successful for the Albuquerque basin (Grauch et al., 2001). These surveys were flown with a fixed-wing aircraft along E-W traverse lines spaced $150 \mathrm{~m}$ apart and $150 \mathrm{~m}$ above ground, with $\mathrm{N}-\mathrm{S}$ tie lines spaced 3-4 km apart. However, Dixie Valley differs from the Albuquerque basin in two important respects. First, faults to be mapped extend to the Stillwater range front (fig. 1), where terrain rises too steeply for fixed-wing aircraft to safely approach at the low altitudes. Second, bedrock beneath the basin fill is shallower and very magnetic, resulting in high amplitude magnetic anomalies that interfere with the expression of the shallow faults.

The first problem dictated the use of a helicopter for the survey. Helicopter systems allow low magnetometer heights because the magnetometer is towed in a bird below the aircraft. A low magnetometer height improves detection of subtle magnetic contrasts, but the increased cost of flying a helicopter encourages wider line spacing to cut down on the total miles flown. These considerations also must be weighed by the need for proper sampling, where a ratio between 1:1 and 2:1 of line spacing to height above magnetic sources is considered adequate in order to sample sources between lines (Reid, 1980). Thus, optimum specifications for the Dixie Valley survey (Table 1) are traverse lines flown generally NW-SE (perpendicular to the range front) spaced $200 \mathrm{~m}(1 / 8 \mathrm{mile})$ apart, a magnetometer height of $120 \mathrm{~m}$ (400 feet) above ground and tie lines oriented NE-SW and spaced $1 \mathrm{~km}$ (5/8 mile) apart. Tie lines are commonly used to "level" the traverse lines and minimize errors inherent in normal flight operations.

The high resolution gained by this survey design also helps solve the second problem of interference by deep magnetic sources by providing good definition of anomalies related to shallow sources, which are associated with local gradients; that is, gradients with limited lateral extent. The local gradients can then be separated from the broader gradients of the deeper sources, even though these sources produce anomalies with much higher amplitudes. The separation comes during the interpretation phase of the project, discussed below. 
Table 1. Specifications of the Dixie Valley high-resolution aeromagnetic survey.

\begin{tabular}{|l|l|}
\hline Dates of Acquisition & January $20-$ February 2,2002 \\
\hline Line Spacing & $\begin{array}{l}200 \mathrm{~m}(\sim 1 / 8 \text { mile }), \text { lines trend } \mathrm{N} 30^{\circ} \mathrm{W}-\text { perpendicular to } \\
\text { regional structures }\end{array}$ \\
\hline Tie lines & $\begin{array}{l}1000 \mathrm{~m}(3280 \mathrm{ft}), \text { lines trend } \mathrm{N} 60^{\circ} \mathrm{E}-\text { parallel to regional } \\
\text { structures }\end{array}$ \\
\hline $\begin{array}{l}\text { Observation height above } \\
\text { ground (average) }\end{array}$ & $120 \mathrm{~m}(\sim 400 \mathrm{ft})$ \\
\hline Instrument/Aircraft & $\begin{array}{l}\text { Cesium-vapor magnetometer with sampling rate of } 0.1 \\
\text { seconds towed below a Bell Jet Ranger helicopter }\end{array}$ \\
\hline Area Surveyed & $\sim 940 \mathrm{~km}^{2}$ \\
\hline Total flight-line length & 5740 line km (3567 miles) \\
\hline
\end{tabular}

\section{DATA ACQUISITION AND PROCESSING}

Under contract to the USGS, Pearson, deRidder and Johnson, Inc. (PRJ) of Lakewood, Colorado, in cooperation with El Aero Services Inc., of Carson City, Nevada, undertook the acquisition and processing of a helicopter borne magnetic data during the period January 20 through February 2, 2002. The survey area covers parts of Dixie Valley, Churchill County, in east central Nevada, and focuses on the area of the geothermal reservoir (fig. 1). Data acquisition was undertaken from January 23 through January 31, 2002 and eighteen survey flights over 9 days were needed to complete the acquisition of 5740 line kilometers (3567 miles) of airborne data. Weather and geomagnetic conditions were generally favorable during the fieldwork. Final data processing was completed by the last week of February 2002. Data acquisition, processing procedures, and digital data from the survey are described and available from USGS and PRJ (2002).

The final, processed, total-field magnetic flight line data were gridded using a minimum curvature routine (Webring, 1981) with a grid spacing of 50 meters, approximately one-fourth of the line spacing of the survey. The data are displayed as a color shaded-relief image, with illumination from the northwest (fig. 2). 


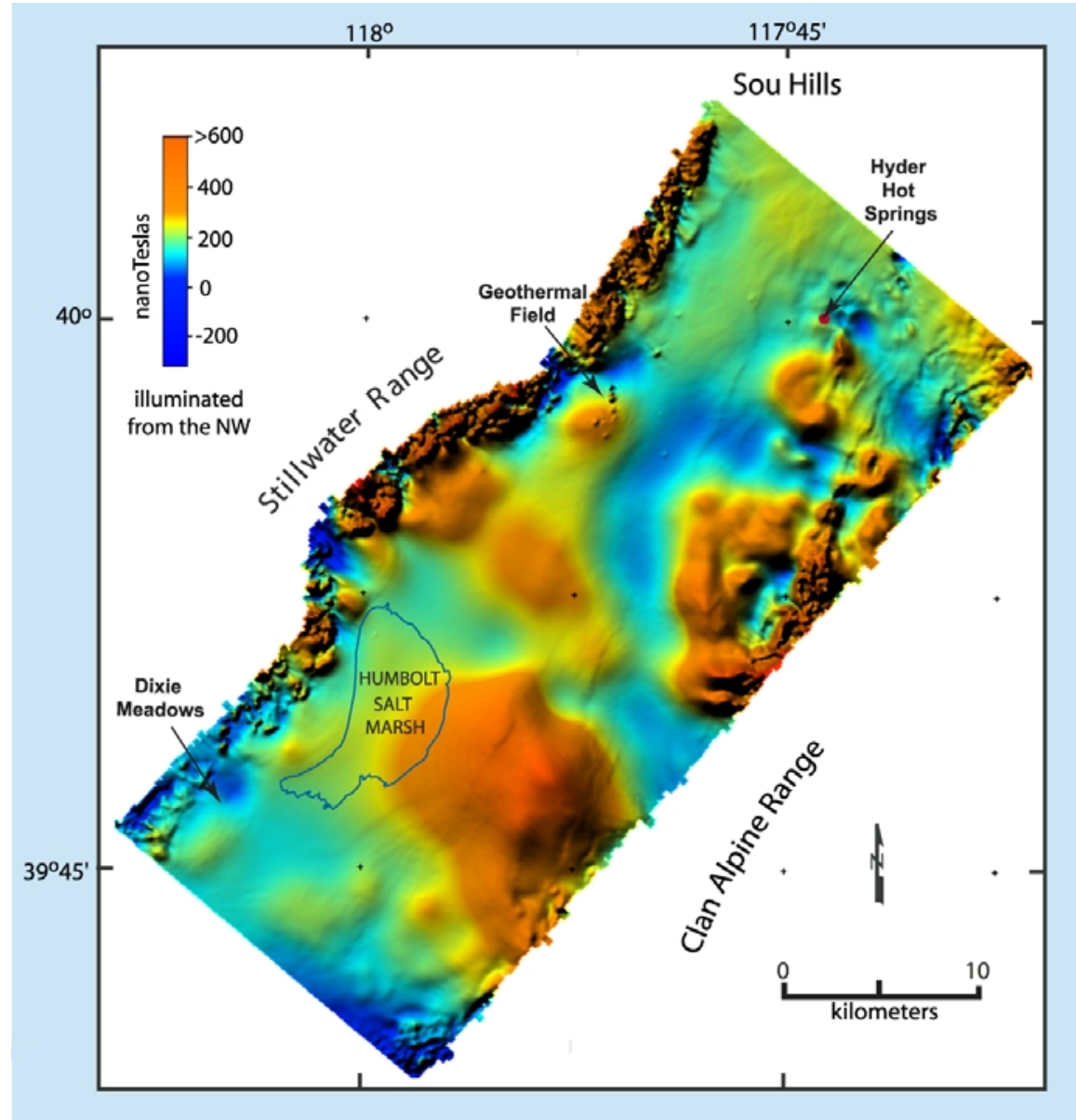

Figure 2. Total-field magnetic data after final data processing, shown in color shaded-relief, illuminated from the northwest. Small "pock-like" anomalies, mainly in the geothermal field, are due to anthropogenic metal structures. 


\section{INTERPRETATION METHODS}

Several interpretation methods were applied with the final goal of enhancing the signature of shallow faults and estimating their depths. The methods included reduction-to-pole, gradient window, anomaly separation, and depth estimation using horizontal gradients.

\section{Reduction-to-pole}

A reduction-to-pole (RTP) transformation is standardly applied to aeromagnetic data to minimize polarity effects (Blakely, 1995). These effects are manifested as a shift of the main anomaly from the center of the magnetic source and are due to the vector nature of the measured magnetic field. The RTP transformation usually involves an assumption that the total magnetizations of most rocks align parallel or anti-parallel to the Earth's main field (declination $=15^{\circ}$, inclination $=64^{\circ}$ for the study area). This assumption probably works well for the Tertiary units in the survey area, which are the focus of interpretation. The RTP aeromagnetic data, computed from the grid of total-field magnetic data, are shown in Figure 3.

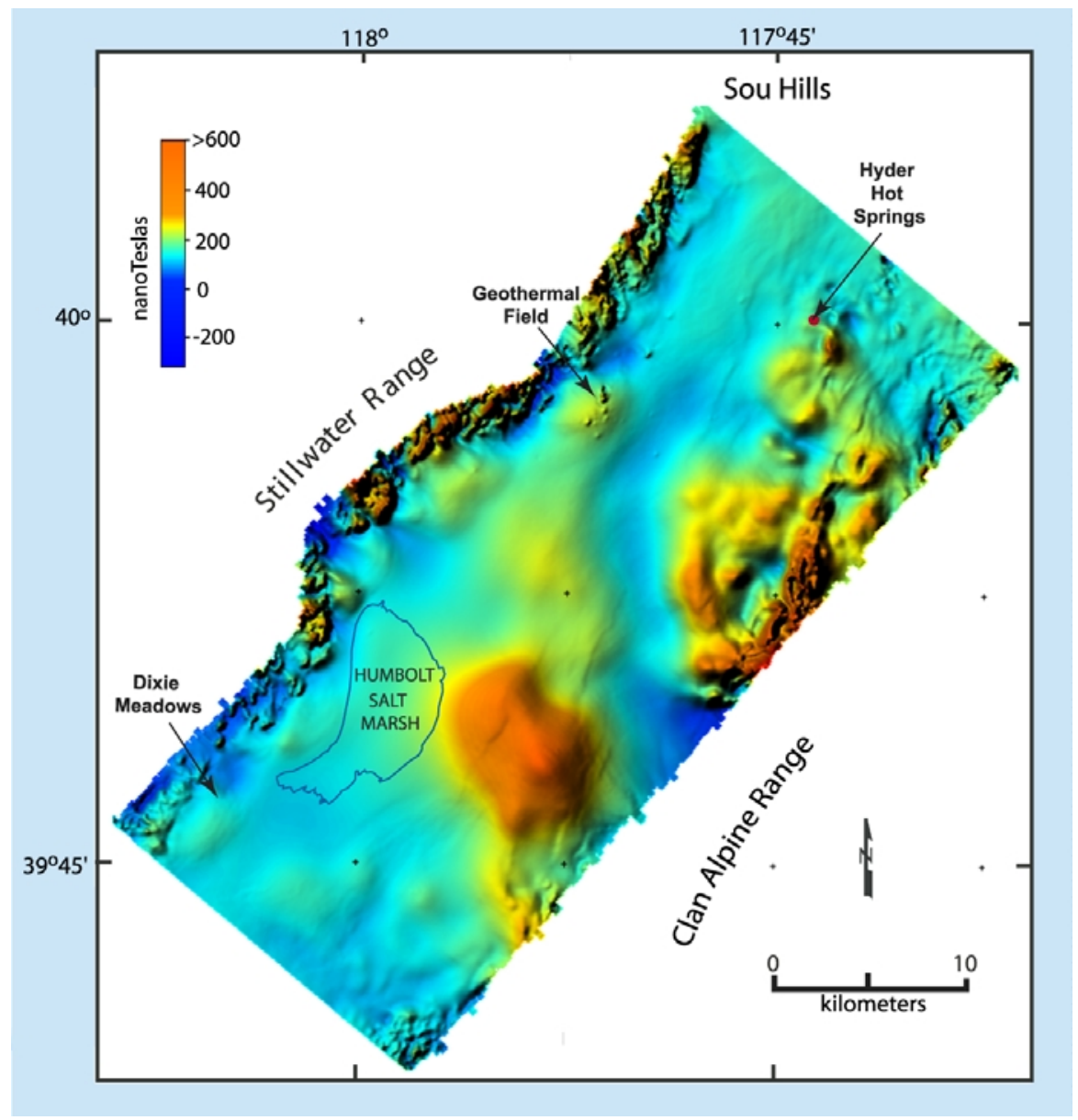

Figure 3. Reduced-to-pole (RTP) aeromagnetic data shown in color shaded-relief, illuminated from the northwest. 


\section{Gradient Window Method}

Both the total-field and RTP magnetic data reveal subtle, northeast-trending linear anomalies superposed on the larger magnetic anomalies (figs. 2 and 3). These anomalies correspond well to mapped faults that offset basin-fill sediments (Smith et al., 2002). To enhance the signature of these faults, the gradient window method was applied (Grauch and Johnston, 2002), a modification of the horizontal-gradient method. The horizontal-gradient method (Cordell and Grauch, 1985; Blakely and Simpson, 1986) is based on a principle from gravity methods that steep gradients occur over near-vertical contacts between units with differing physical properties. For magnetic data, the same principle can be applied after transforming the data into a form that is mathematically similar to gravity data, called pseudogravity (Baranov, 1957). Local peaks (or ridges) in the magnitude of the horizontal gradient of pseudogravity give the locations of steepest gradients, intuitively similar to taking the first derivative of a curve. A modification of the method, which isolates the horizontal-gradient magnitudes associated with short-wavelength anomalies (Grauch and Johnston, 2002), was applied to the Dixie Valley data after transforming to pseudogravity (fig. 4).

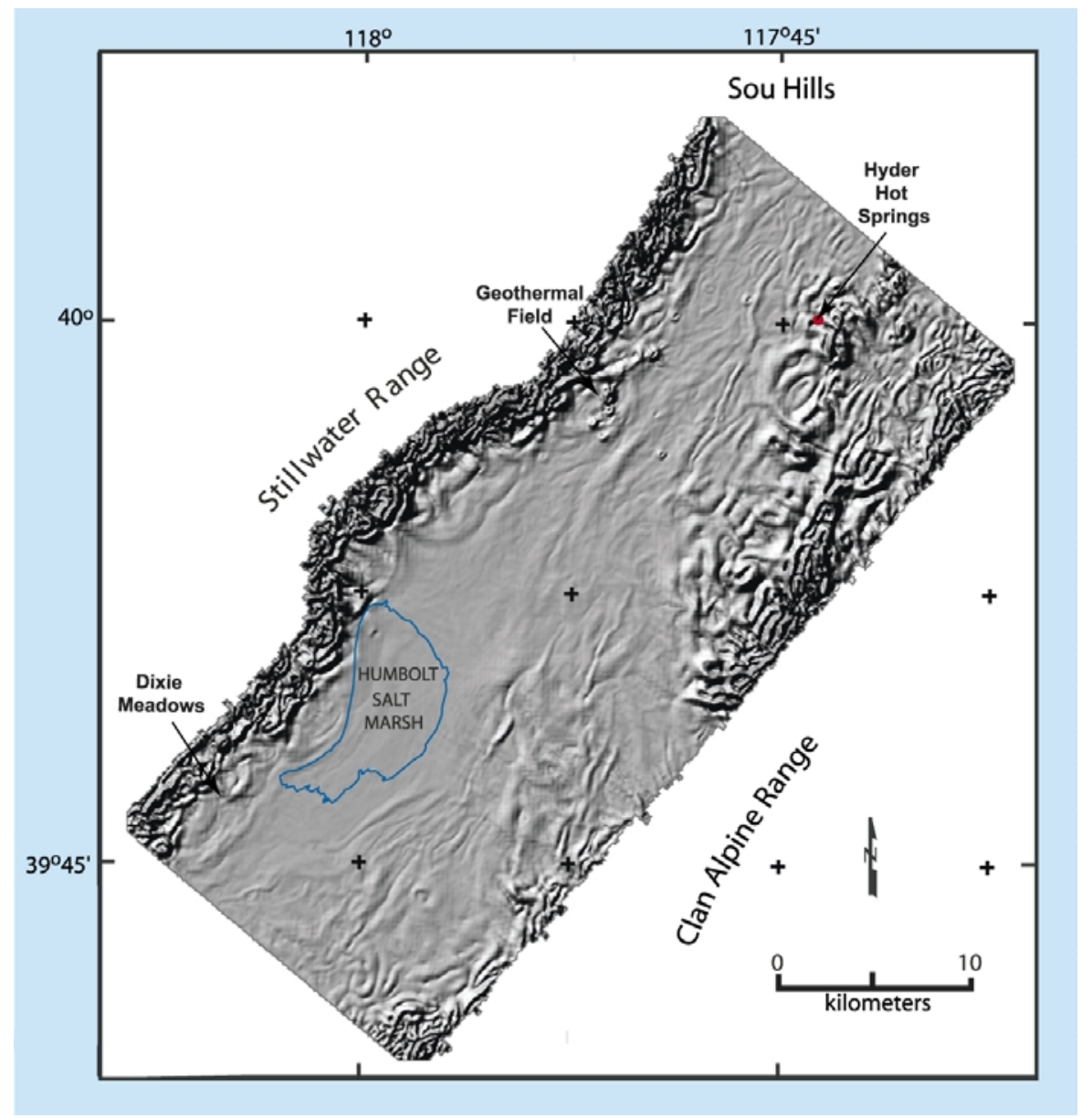

Figure 4. Shaded-relief image of the HGM associated with local (shallow) features, computed from the pseudogravity using the residual after removing a plane from a 1 x $1 \mathrm{~km}$ moving window in the gradient window method. Illuminated from the NW. 
Linear anomalies related to faults are clearly evident after application of the gradient window method (fig. 4). The enhancement provides a more comprehensive view of fault patterns than previously available by any other method. However, further analysis was required to give estimates of the depths of interpreted faults. The first step of this analysis was to separate the anomalies of the map based on anomaly width.

\section{Anomaly Separation}

A common practice in magnetic interpretation is to separate anomalies based on their wavelengths, or anomaly widths. This practice is based on a rule of thumb that the short wavelengths (detailed features) are produced by shallow sources, whereas the long wavelengths (broad features) are produced by deep sources. A method called matched filtering was used to separate the aeromagnetic data into several depth components, based on the match of anomaly widths to the widths of anomalies produced by layers of hypothetical magnetic sources at different depths (Syberg, 1972; Phillips, 2001). The data were separated into three components (fig. 5), using matches to hypothetical layers at $280 \mathrm{~m}$ (919 ft), $2.1 \mathrm{~km}(6890 \mathrm{ft})$, and $4.6 \mathrm{~km}$ $(15,092 \mathrm{ft})$ depths.

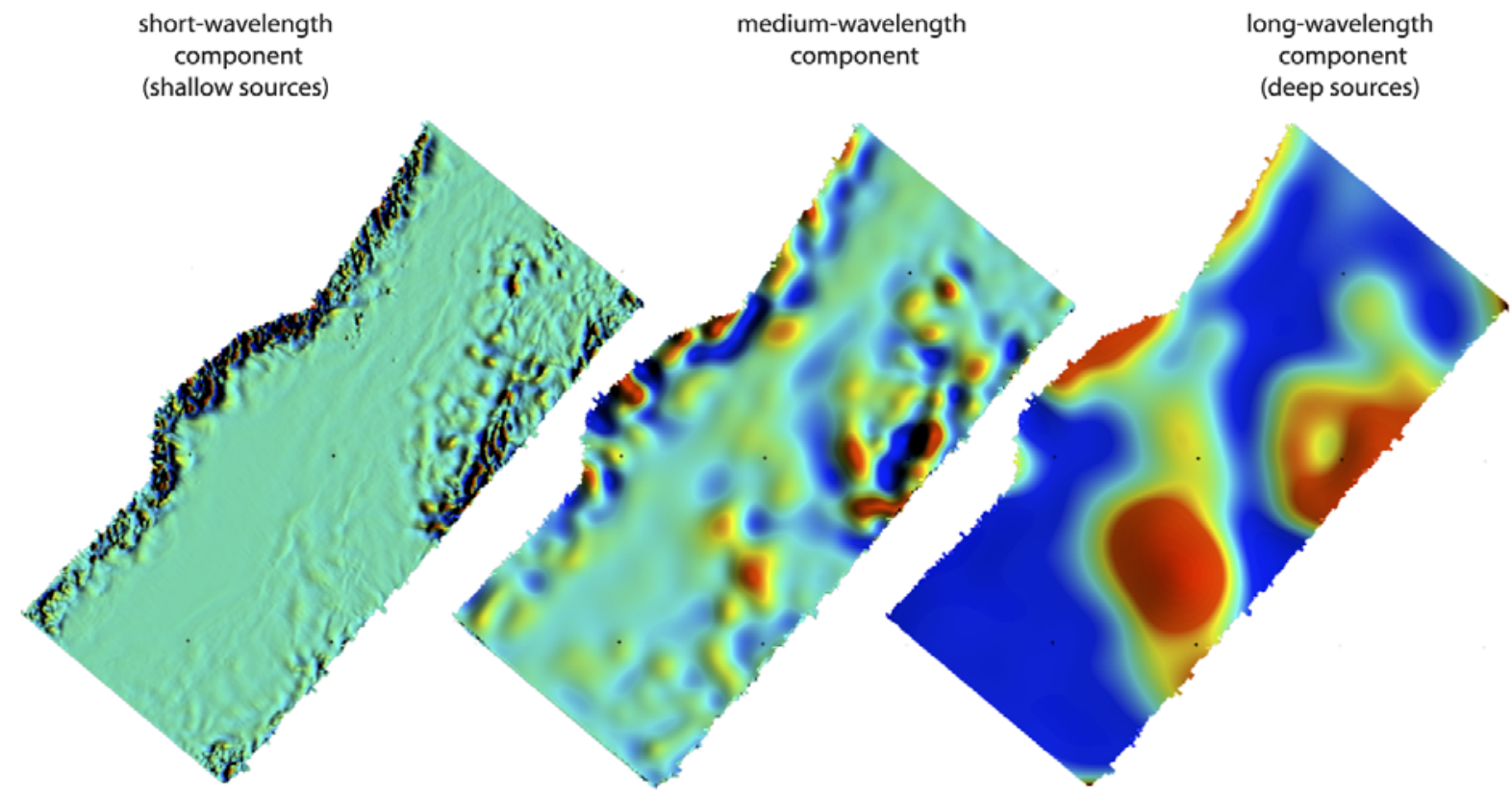

Figure 5. Separation of the RTP aeromagnetic data into different anomaly-width (depth) components using matched filtering. 


\section{Depth Estimation}

Depths were estimated from the two shallowest depth components in order to examine anomalies due to shallow faults. The horizontal-gradient depth (HDEP) analysis, as implemented by Phillips (1997), was utilized for the depth estimation, because it is designed to focus on gradients related to linear features. The HDEP method uses the HGM of the RTP aeromagnetic and pseudogravity grids to estimate strikes of and depths to thick and thin edges, respectively (Phillips, 2000). The method relies on the general principle that shallow sources produce anomalies with steep gradients, whereas deep sources produce anomalies with broad gradients. Depth estimates from the RTP magnetic and pseudogravity data estimate the minimum and maximum depths to the top edge of the layer, respectively (Phillips, 2000).

Depths estimated from the shallowest depth component ranged from 0 (the surface) to about $250 \mathrm{~m}(820 \mathrm{ft})$. Depths greater than $250 \mathrm{~m}$ but less than about $1.5 \mathrm{~km}(4921 \mathrm{ft})$ were estimated from the middle depth component. The locations of the inferred faults from the HGM map (fig. 4), with color coding based on the depth estimates provided by the HDEP method are shown in Figure 6.

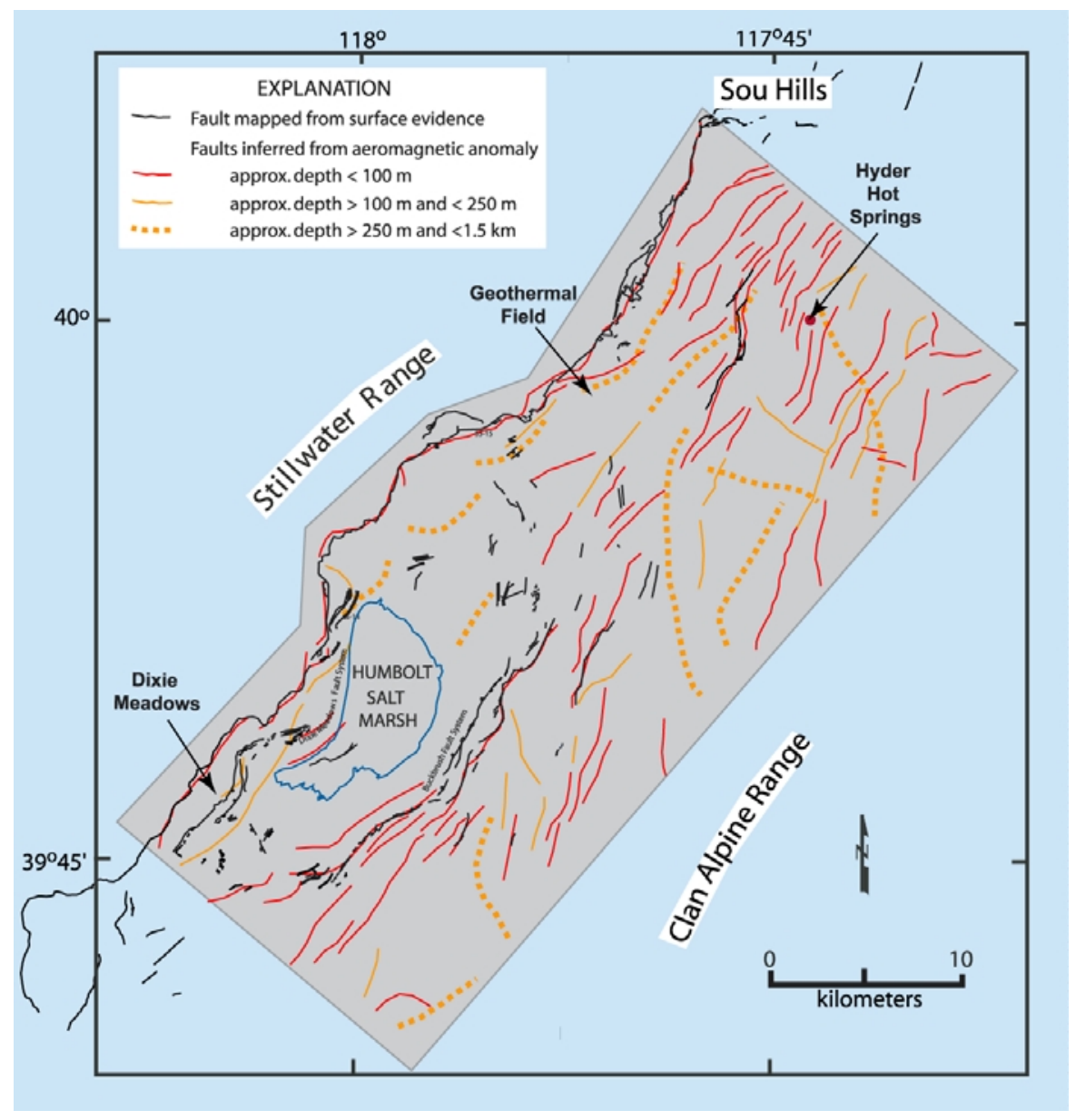

Figure 6. Interpreted faults, color-coded according to estimated depth, compared to faults mapped at the surface from Smith et al. (2001). 


\section{SUMMARY OF RESULTS}

High-resolution aeromagnetic data over the Dixie Valley geothermal field show many subtle, generally northeast-striking, linear to sinuous features superposed on large-amplitude anomalies produced by magnetic bedrock (gabbroic complex and volcanic rocks). The linear anomalies are akin to those demonstrated in high-resolution aeromagnetic data from the Albuquerque basin (Grauch, 2001) and similarly correspond well to geologically mapped faults. Thus, these anomalies can be used to extend faults beyond their mapped surface exposure or infer previously unknown faults where they are covered by thin surficial deposits. However, unlike the Albuquerque basin case, many of the linear anomalies for Dixie Valley were not completely revealed by shaded-relief imagery. Further interpretation, using gradients and anomaly separation, were required to separate them from the influence of the large-amplitude anomalies. The gradient window method, in particular, worked well to reveal a comprehensive pattern of faulting within the basin fill. Anomaly separation prior to depth estimation increased the resolution of determining the depth range of shallow sources where there was interference from deeper sources. All the methods together provided a view of the patterns and general depth ranges of intrabasin faults within the geothermal field that will aid research on the relation of faults to the geothermal reservoir.

A key to the success of this airborne survey was its regional coverage and the use of a helicopter in data acquisition. The survey was an economical and efficient way to cover a large amount of ground, which was critical to gaining the detailed pattern of faulting in map view across the basin. In addition, the helicopter system gained high resolution of magnetic data right up to the range front fault, which could not have been accomplished using a fixed-wing aircraft.

\section{LIMITATIONS}

Although there are always errors in data acquisition and processing, by far the greatest limitations of the results come during the interpretation process. Magnetic data reflect the variations in the Earth's magnetic field that arise from the distribution of magnetic materials in the ground. The first step in interpretation is determining that distribution; the second is understanding its geologic association. Ambiguity is common in the first step; independent information, subjectivity, experience, or a combination of these are required for the second step. Below is a discussion of the limitations of the interpretations presented in this report.

The linear anomalies, where they are isolated from other magnetic sources and from manmade structures (such as pipelines or roads made of foreign materials), may be offset from the surface expression of faults for several reasons: (1) the magnetic contrast may be related to sedimentation near the fault rather than to offset of material at the fault zone; (2) the fault may have shallow dip; (3) the fault at the surface may be a separate strand from the one at which the magnetic contrast occurs; or (4) the surface evidence of faulting has migrated away from the fault zone at depth due to erosion or subsequent sedimentation. Conversely, faults mapped at the

surface may have no magnetic expression because (1) the units they offset have similar magnetic properties, or (2) the amount of offset is minimal. In addition, even where faults are expressed magnetically, the sense of fault offset (which side is down) cannot be determined from the magnetic data alone. 
Faults interpreted in the area of high-amplitude magnetic anomalies, such as in the northeastern part of the survey area and along the range front, are subject to additional problems. Because the sources of these anomalies are so magnetic, they may produce lows on the aeromagnetic map where they end abruptly ("edge effects") or in topographic valleys ("magnetic terrain effects"). Combined with the knowledge that negative magnetic anomalies in the area may be due to strong, reversed remanent magnetization in volcanic units (Smith, 1968; Hudson and Geissman, 1991), faults that abruptly terminate these rocks can be difficult to locate with certainty.

Using horizontal gradients to enhance the locations of sources of the linear anomalies is useful, but interpretation of HGM can be ambiguous due to interference from neighboring sources, the presence of rugged topography, and the common, high variability of magnetic properties. For example, the locations of maxima of HGM can represent the locations of (1) faults, where a magnetic contrast is produced by structural juxtaposition of units; (2) contacts, where the magnetic contrast is produced by the limit of deposition of a magnetic unit against a less magnetic one, such as the edge of a basalt flow; (3) steep topographic slopes, where the magnetic contrast is produced by the interface between rock and air; or (4) abrupt changes in magnetization within one rock unit, produced by primary differences in magnetization or due to secondary destruction or growth of magnetic minerals. In addition, multiple gradients can occur where thin, horizontal sheet-like sources are vertically offset from thicker sources at depth, called a thin-thick layers model (Grauch and others, 2001).

Separating the data into different components is rarely perfect, because there is usually considerable overlap in ranges of anomaly widths. Therefore, depth estimations based on these separations may not be completely accurate. In addition, even where anomalies do not require separation, errors in depth estimation can be as much as $\pm 20 \%$ of estimated depth (Milsom, 1989). The amount of error varies depending on how well the geologic sources match the assumed source type and whether the magnetic anomalies of these sources are mostly isolated from the effects of other sources.

\section{REFERENCES CITED}

Baranov, V., 1957, A new method for interpretation of aeromagnetic maps--pseudogravity anomalies: Geophysics, v. 22, p. 359-383.

Blakely, R. J., 1995, Potential theory in gravity and magnetic applications: Cambridge Univ. Press.

Blakely, R. J., and Simpson, R. W., 1986, Locating edges of source bodies from magnetic or gravity anomalies: Geophysics, v. 51, p. 1494-1498.

Cordell, Lindrith, and Grauch, V. J. S., 1985, Mapping basement magnetization zones from aeromagnetic data in the San Juan Basin, New Mexico, in Hinze, W. J., Ed., The Utility of Regional Gravity and Magnetic Maps: Society of Exploration Geophysicists, p. 181197. 
Grauch, V.J.S., 2001, High-resolution aeromagnetic data, a new tool for mapping intrabasinal faults: An example from the Albuquerque basin, New Mexico: Geology, v. 29, p.367370.

Grauch, V.J.S., Hudson, M.R., and Minor, S.A., 2001, Aeromagnetic expression of faults that offset basin fill, Albuquerque basin, New Mexico: Geophysics, v. 66, p.707-720.

Grauch, V.J.S., and Johnston, C.S., 2002, Gradient window method: A simple way to isolate regional from local horizontal gradients in potential-field gridded data: 72nd Annual International Meeting, Society of Exploration Geophysicists, Expanded Abstracts, in press.

Hudson, M. R., and Geissman, J.W., 1991, Paleomagnetic evidence for the age and extent of middle Tetiary counterclockwise rotation, Dixie Valley region, west central Nevada: Journal of Geophysical Research, v. 96, no. B3, p. 3979-4006.

Milsom, J., 1989, Field Geophysics, Geological Society of London Handbook: Halsted Press, New York, 182 pp.

Phillips, J. D., 1997, Potential-field geophysical software for the PC, version 2.2: U. S. Geological Survey Open-File Report 97-725, available from ftp://greenwood.cr.usgs.gov/pub/open-file-reports/ofr-97-0725/pfofr.htm

Phillips, J.D, 2000, Locating magnetic contacts: a comparison of the horizontal gradient, analytic signal, and local wavenumber methods: $70^{\text {th }}$ International Annual Meeting, Society of Exploration Geophysicists Expanded Abstracts, p. 402-405.

Phillips, J.D., 2001, Designing matched bandpass and azimuthal filters for the separation of potential field anomalies by source region and source type: $15^{\text {th }}$ Geophysical Conference and Exhibition, Australian Society of Exploration Geophysicists, Extended Abstracts, CD-ROM.

Reid, A. B., 1980, Aeromagnetic survey design: Geophysics, 45, 973-976.

Smith, R. P., Grauch, V. J. S., and Blackwell, D. D., 2002, Preliminary Results of a HighResolution Aeromagnetic Survey to Identify Buried Faults at Dixie Valley, Nevada: Geothermal Resources Council Transactions, v. 26, p. 543-546.

Smith, R.P., Wisian, K.W., and Blackwell, D.D., 2001, Geologic and geophysical evidence for intra-basin and footwall faulting at Dixie Valley, Nevada: Geothermal Resources Council Transactions, v. 25, p. 323-326.

Smith, T.E., 1968, Aeromagnetic measurements in Dixie Valley, Nevada; Implications on BasinRange structure; Journal of Geophysical Research, v.73, p.1321-1331.

Syberg, F. J. R., 1972, A Fourier method for the regional-residual problem of potential fields: Geophysical Prospecting, v. 20, p. 47-75. 
U. S. Geological Survey and Pearson, deRidder, and Johnson, Inc., 2002, A helicopter-borne magnetic survey over Dixie Valley geothermal field, Nevada: U.S. Geological Survey Open-File Report 02-374, available from ftp://greenwood.cr.usgs.gov/pub/open-filereports/ofr-02-0374.

Webring, M., 1981, MINC: A gridding program based on minimum curvature: U. S. Geological Survey Open-File Report 81-1224, 41 pp. 